\title{
Aortic Root Reconstruction with a New Dacron Graft Featuring Prefabricated Coronary Side Branches
}

\section{Lessons Learned from the Cabrol Procedure}

\author{
Domenico Calcaterra, $\mathrm{MD}^{1 *}$, Mohammad-Ali Jazayeri, MD${ }^{1}$, Joseph W. Turek, MD², \\ Kalpaj R. Parekh, MD², Mohammad Bashir, MD², Karam Karam, MD², Robert S. Farivar, MD ${ }^{1}$ \\ ${ }^{1}$ Minneapolis Heart Institute Cardiothoracic Surgery, Abbott Northwestern Hospital, Hennepin County Medical Center, Minneapolis, \\ Minnesota, USA \\ ${ }^{2}$ Department of Cardiothoracic Surgery, University of lowa Carver College of Medicine, lowa City, lowa, USA
}

\begin{abstract}
Background: Coronary button reimplantation can represent a technical challenge of aortic root reconstruction that can be associated with significant morbidity and mortality. With the goal of simplifying coronary reimplantation and reducing the incidence of related complications, we designed a new Dacron graft with prefabricated coronary branches to minimize coronary artery mobilization and prevent the potential mechanical complications of reattachment to the body of the graft. Methods: Between June 2010 and May 2012, we implanted the graft in eight patients (six males, two females) ranging in age from 42-68 years (mean, 54 years). Six procedures were modified Bentall reconstructions, and two procedures were valvesparing root replacements using the reimplantation technique.

Results: There were no complications and no morbidity or mortality related to coronary reattachment. All patients were alive and doing well at a mean follow-up of 26 months (range, 17-38 months). At an extended mean follow-up of 42 months (range, 25-56 months), one patient died of stroke-related complications. No radiologic or clinical evidence of impairment of coronary perfusion was identified in any patient.

Conclusions: The use of this new graft model may simplify the technique of root reconstruction and
\end{abstract}

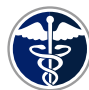

Fax +1 2037853552

E-Mail: aorta@scienceinternational.org

http://aorta.scienceinternational.org
(C) 2017 AORTA

Published by Science International Corp. ISSN 2325-4637

Accessible online at:

http://aorta.scienceinternational.org potentially lower the incidence of mechanical complications related to coronary button reimplantation. Copyright @ 2017 Science International Corp.

\section{Key Words:}

Aortic root - Bentall procedure - Dacron graft • Cabrol procedure

\section{Introduction}

Aortic root replacement (ARR) is a well-described and highly effective technique for treating aortic root pathologies with excellent long-term outcomes and reported mortality ranging between $4-10 \%$ in specialized aortic centers [1-3]. Coronary button reimplantation is arguably one of the most challenging aspects of ARR operations, requiring mobilization and reattachment of the coronaries to the root graft. Reimplantation can be complicated by damage to the coronary buttons, coronary occlusion or malperfusion, and bleeding. The potential catastrophic complications of coronary reimplantation after ARR can occur in the immediate postoperative period $[4,5]$ or in the weeks and months following the operation

* Corresponding Author:

Domenico Calcaterra, MD, PhD

Minneapolis Heart Institute at Abbott Northwestern Hospital,

Hennepin County Medical Center, Cardiothoracic Surgery

701 Park Avenue, 05, Minneapolis, Minnesota 55415, USA

Tel.: +1 612863 6900; Fax: +1 612863 6899; E-Mail: domenico.calcaterra@hcmed.org 
[6-9]. In the present study, we describe our experience performing ARR with an experimental polyester graft featuring prefabricated coronary branches in an effort to prevent complications.

\section{Materials and Methods}

\section{Patient Profile}

In a single-surgeon experience of 134 proximal aortic replacements performed since 2008, 55 were root replacements. Of these, 17 (30\%) required a variation of technique for coronary reimplantation (hemi-Cabrol Dacron graft or saphenous vein "jump" graft) of one or both coronary ostia as compared with the classic button Bentall reconstruction [10]. From June 2010 to April 2012, eight patients underwent ARR using a custom-made Dacron graft with prefabricated coronary side branches (Figure 1). This study was approved by the Institutional Review Board at the University of lowa Hospitals and Clinics, and informed consent was obtained from each patient. Two of the patients (25\%) were female. Median age at the time of operation was 56.5 years (range, $42-68$ years). There were six modified Bentall procedures (four with mechanical and two with bioprosthetic valves) and two valve-sparing ARRs (Table 1). Seven operations were performed electively for aortic root aneurysm, and one was performed emergently for acute Type A aortic dissection. In the elective group, three patients had a root aneurysm associated with aortic valve insufficiency, and two had a root aneurysm associated with aortic valve stenosis. The remaining two patients in the elective group had undergone prior sternotomies, one for aortic valve replacement and the other for an acute Type A dissection. In the former, there was an aortic root aneurysm with a prosthetic valve mismatch ( $21 \mathrm{~mm}$ mechanical); in the latter, there was a residual aortic root dissection associated with prominent root dilation and severe aortic valve insufficiency.
A
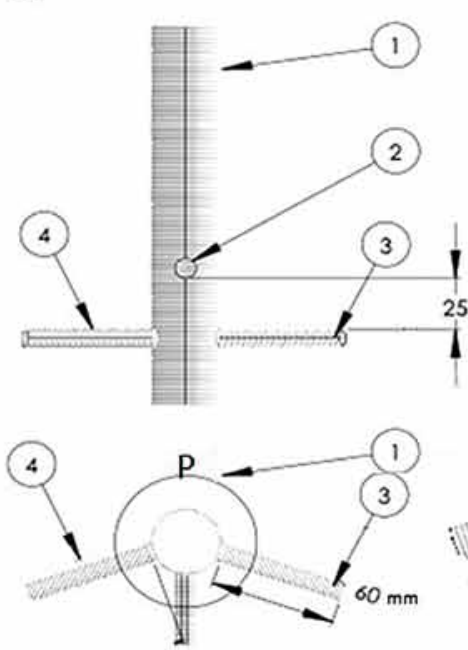

A
(1) Main body

(2) Side-port branch

(3) Left coronary branch

(4) Right coronary branch

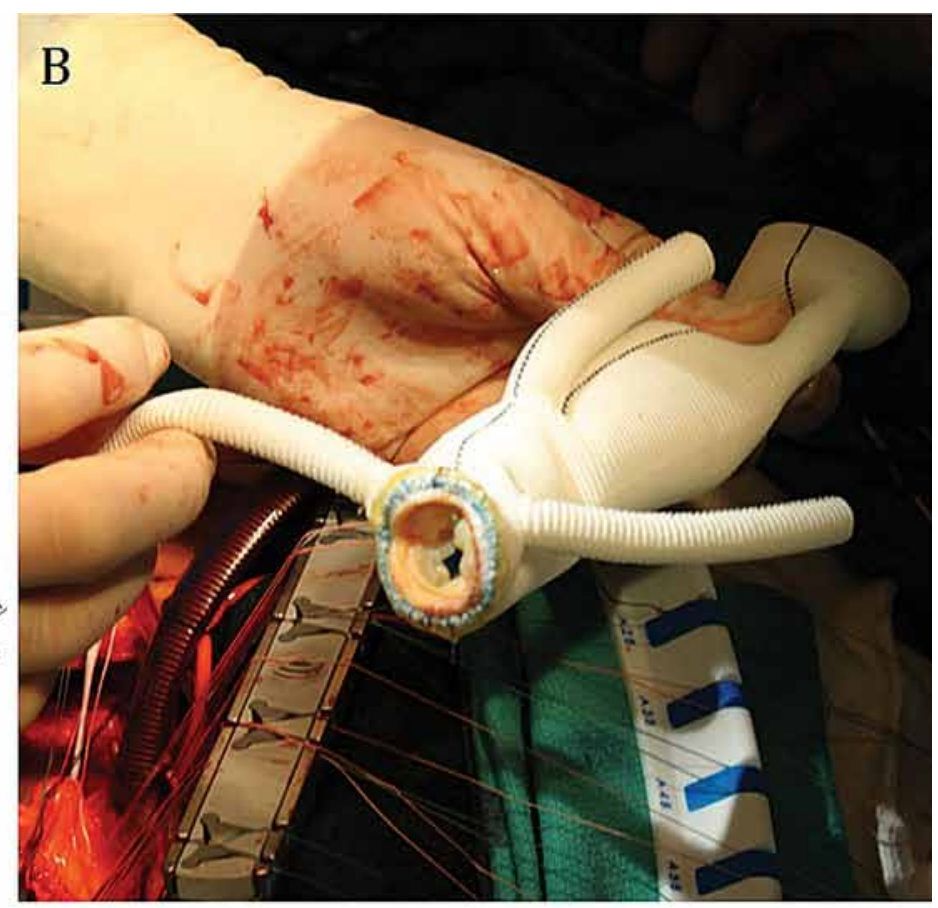

P: posterior

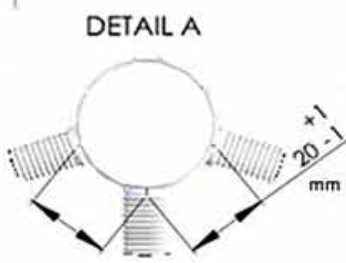

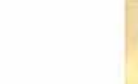


Table 1. Patient characteristics and follow-up data.

\begin{tabular}{|c|c|c|c|c|c|c|c|}
\hline Patient & $\begin{array}{l}\text { Age } \\
\text { (years) }\end{array}$ & Sex & Diagnosis & $\begin{array}{c}\text { Graft size } \\
(\mathrm{mm})\end{array}$ & $\begin{array}{l}\text { Valve } \\
\text { type }\end{array}$ & $\begin{array}{l}\text { Valve size } \\
\text { (mm) }\end{array}$ & $\begin{array}{c}\text { Follow-up } \\
\text { (months) }\end{array}$ \\
\hline 1 & 56 & M & $\begin{array}{l}\text { Root aneurysm } \\
\text { Severe Al }\end{array}$ & 30 & Mech & 25 & 56 \\
\hline 2 & 42 & M & $\begin{array}{l}\text { Root aneurysm } \\
\text { Moderate Al }\end{array}$ & 32 & VS & $N / A^{*}$ & 50 \\
\hline 3 & 61 & $\mathrm{~F}$ & $\begin{array}{l}\text { Root aneurysm } \\
\text { AV endocarditis }\end{array}$ & 28 & Bio & 23 & 48 \\
\hline 4 & 46 & $\mathrm{~F}$ & $\begin{array}{l}\text { Root aneurysm } \\
\text { Severe Al }\end{array}$ & 30 & Mech & 25 & 45 \\
\hline 5 & 58 & M & $\begin{array}{l}\text { Root aneurysm } \\
\text { Severe AS }\end{array}$ & 28 & Mech & 23 & 42 \\
\hline 6 & 47 & M & Acute Stanford Type A dissection & 28 & Mech & 25 & 38 \\
\hline 7 & 57 & $M$ & $\begin{array}{l}\text { Root aneurysm } \\
\text { Prosthetic valve mismatch }\end{array}$ & 30 & $\mathrm{Bio}^{\wedge}$ & 25 & 36 \\
\hline 8 & 68 & $M$ & $\begin{array}{l}\text { Root aneurysm } \\
\text { Chronic Stanford Type A } \\
\text { dissection }\end{array}$ & 32 & VS^ & $N / A^{*}$ & 25 \\
\hline
\end{tabular}

$\mathrm{Al}=$ aortic insufficiency; $\mathrm{AS}=$ aortic stenosis; Mech = mechanical; Bio = bioprosthetic; $\mathrm{VS}=$ valve-sparing.

*Patients underwent valve-sparing operations.

$\wedge$ Redo operations.

\section{Custom Dacron Graft with Prefabricated Coronary Side Branches}

The graft was custom-made by MAQUET Cardiovascular, LLC (Wayne, NJ, USA) in sizes of 28,30 , and $32 \mathrm{~mm}$ (Figure 1A). Two, 8-mm diameter prefabricated branches were provided for coronary button anastomosis (Figure 1B). A third prefabricated branch was included as a side port for direct graft cannulation or for de-airing after reconstruction. Prosthetic valves were sewn into the graft in the operating room after the correct graft and valve size were determined [11].

\section{Surgical Technique}

The reconstruction technique using the custom Dacron graft has previously been reported in detail [11]. Cardiopulmonary bypass was established in all cases reaching mild hypothermia, except for the case of the acute Type A dissection, for which deep hypothermic circulatory arrest was established at a core temperature of $18^{\circ} \mathrm{C}$, maintaining selective cerebral perfusion through the innominate artery at a rate of $10 \mathrm{ml} / \mathrm{kg} / \mathrm{min}$ during completion of the "open" distal anastomosis. In this case, axillary arterial cannulation was utilized as opposed to cannulation of the distal ascending aorta, which was utilized in all other cases. Venous return was achieved through cannulation of the right atrial appendage using a multi-stage MC2X venous cannula (Medtronic Inc., Minneapolis, MN, USA). The left ventricle was vented in all cases through the right superior pulmonary vein. Myocardial protection was obtained by intermittent delivery of anterograde and retrograde cold blood cardioplegia. The aorta was transected at the sino-tubular junction. The coronary buttons were carefully prepared leaving a small cuff of aortic tissue, and the aortic annulus was sized. The selected valve was sewn into the graft matching the size of the aorta using a double layer of continuous 4-0 Prolene suture. The newly constructed valved conduit was sewn to the aortic annulus achieving appropriate alignment of the coronary branches to reach the native coronary buttons. At this point, reattachment of the left branch of the Dacron graft to the left main coronary button was approached. The graft branch 
intended for the left coronary ostium was trimmed to the appropriate length and sewn into place using a 5-0 Prolene running suture. The distal anastomosis to the native aorta was completed next, followed by completion of the anastomosis of the right branch graft to the right coronary button. To establish the appropriate length of the graft branch, the heart was distended, and the graft branch was trimmed accordingly. The anastomosis was completed with a running 5-0 Prolene suture. To check for adequate hemostasis at the anastomotic sites, cardioplegia was administered through the side-port branch of the graft, and the native aorta was subsequently unclamped, applying vent suction to the side port branch for de-airing purposes.

\section{Results}

Among the eight cases, there were no immediate or delayed postoperative complications, including myocardial infarction, respiratory insufficiency, stroke, or death. At a mean follow-up period of 25.5 months (range, 17-38 months), all patients were noted to be alive and doing well. Echocardiograms, which were performed for all patients during hospitalization and at 6-month and 1-year follow-ups, showed no significant changes in left ventricular function compared with preoperative status as well as no new evidence of new wall-motion abnormalities. Angiographic computed tomography with coronary imaging, which was performed for all patients at the first follow-up visit and 6 months after hospital discharge, showed no defect of coronary perfusion. One patient who underwent a redo operation with a valve-sparing root replacement for a chronic Type A dissection showed mild-to-moderate residual aortic valve insufficiency. At an extended mean follow up of 42 months (range, 25-56 months), this patient died due to stroke-related complications 25 months after surgery. No other patients required further surgical reintervention or showed any clinical or radiologic signs of impairment of coronary perfusion.

\section{Discussion}

Despite improvements in outcomes over the past decade, ARR is still associated with considerable morbidity and mortality. Although many modifications in surgical technique based on the original Bentall-De Bono procedure [12] have reduced the incidence of complications, reimplantation of the coronary buttons still poses a significant challenge and may be responsible for the significant rate of associated complications. The occurrence of ventricular dysfunction, perioperative myocardial infarction, or surgical bleeding depends on the technical difficulty of coronary reimplantations $[3-5,11,13]$. Damage to the coronary buttons during mobilization and tension or kinking after completion of the anastomosis can cause coronary malperfusion [3, $4,13-15]$. These mechanisms are illustrated in detail by Elefteriades' group in their report describing "rescue coronary artery bypass grafting" to treat acute coronary insufficiency after ARR (Figure 2) [4, 16]. These challenges can be more difficult in redo operations or for porcelain aortas in which the presence of scar tissue and aortic calcification obstructs mobilization of the coronaries [13, 17, 18]. Similarly, in valve-sparing reconstructions, the presence of aortic valve leaflets re-implanted into the prosthetic graft may require more extensive coronary mobilization to find the appropriate re-attachment location on the Dacron graft. Furthermore, in cases of acute aortic dissection, mobilization and reimplantation of the coronaries involved by the dissection can result in irreparable damage to the buttons. For these reasons, different techniques have been proposed to reduce the rate of complications associated with coronary reimplantation. For instance, Westaby and colleagues propose a technique using a "pericardial hood" extension added to the right coronary anastomosis (Figure 3A) [14] to avoid kinking or tension, whereas others advocate the use of a coronary vein bypass interposed between the main aortic graft and the right coronary button [2].

The Cabrol reconstruction represents a more radical approach to the problem [19] and is meant to obviate the challenges of coronary reimplantation when mobilization of the coronaries is cumbersome $[2,13,17-19]$. Nevertheless, this technique may be associated with a higher rate of mortality and morbidity compared with modified Bentall reconstruction. In particular, both early and long-term results suggest that Cabrol reconstruction is inferior $[2,20]$, 

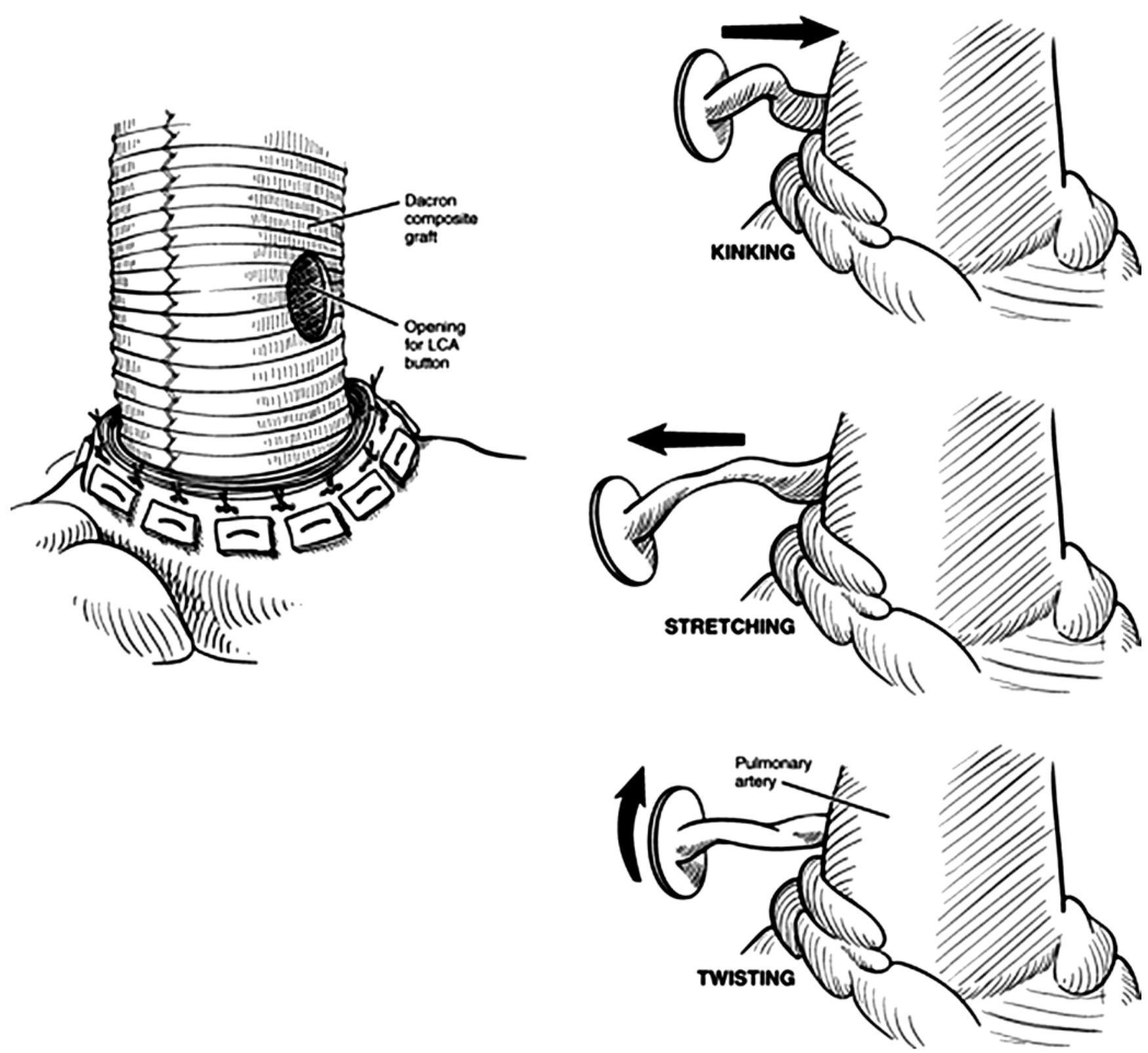

Figure 2. Proposed mechanisms of coronary blood flow compromise during coronary button mobilization and anastomosis (reprinted with permission from Shahriari et al. [4]).

with a frequent incidence of Cabrol graft-conduit thrombosis and formation of anastomotic pseudoaneurysms $[2,21,22]$. This could be explained by the fact that the procedure is performed as a "bail-out" in place of the modified Bentall reconstruction in more complex cases or that normal flow-dynamics of the coronary circulation are compromised within the Cabrol graft conduit $[2,23]$. In a long-term follow-up study of seven patients with Cabrol reconstruction, Knight and colleagues observed lower flow in the right side of the Cabrol graft than in the left side, which correlated with a high rate of right coronary ischemia [22]. Coronary flow hemodynamic studies show that resting coronary blood flow is approximately $5-7 \%$ of the entire cardiac output and that flow in the left and right coronary systems have different characteristics. A peak flow of $200-400 \mathrm{ml} / \mathrm{min}$ is reached in the left main coronary artery during diastole, where- 


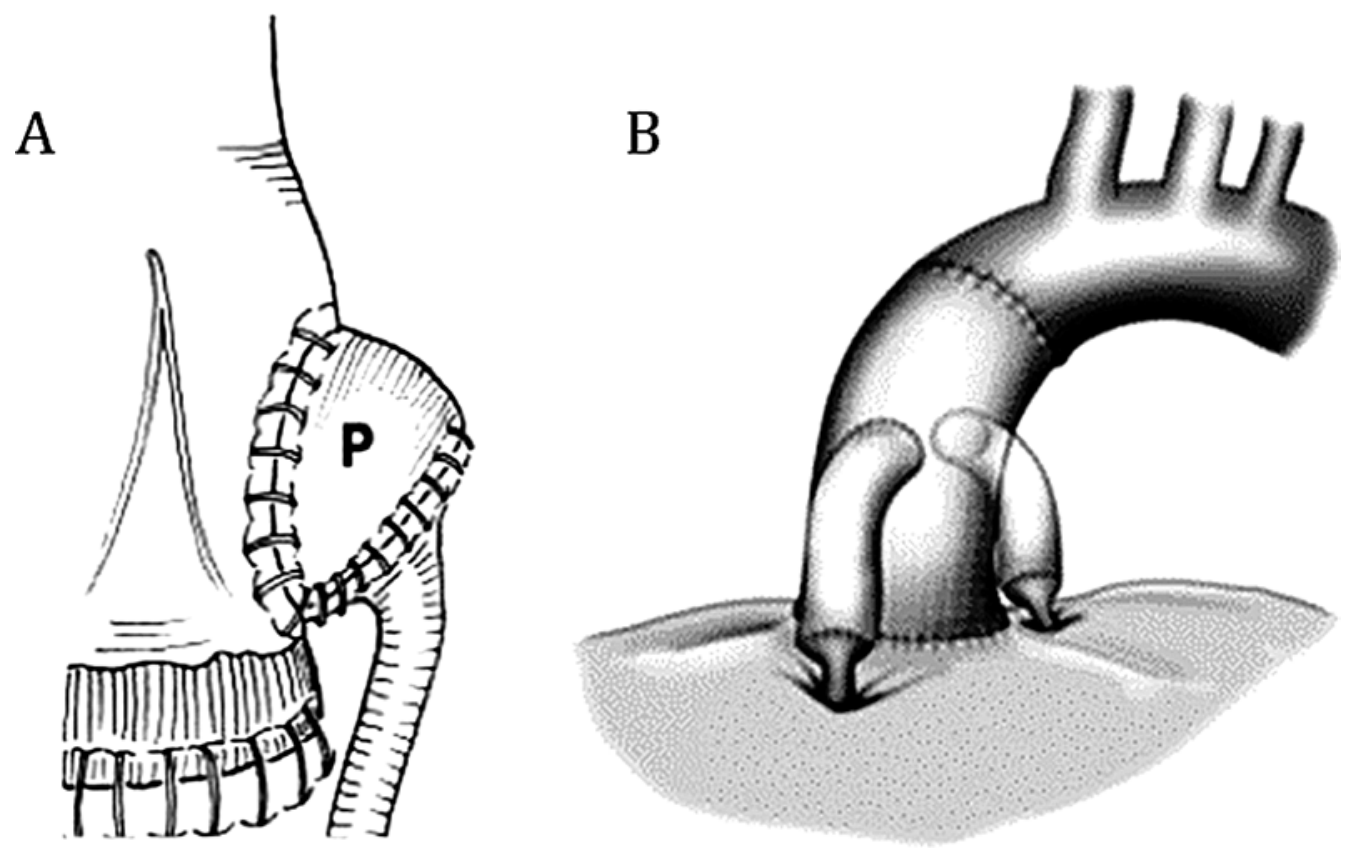

Figure 3. Alternative methods to minimize coronary button mobilization in aortic root replacement, including (Panel A) placement of a pericardial hood (reprinted with permission from Westaby et al. [3]) and (Panel B) the "legs" technique for coronary button anastomosis (reprinted with permission from Kourliouros et al. [2]).

as a peak flow of $40-60 \mathrm{ml} / \mathrm{min}$ is reached in the proximal right coronary artery during systole (Figure 4). The different flow-dynamics between the left and the right coronary arteries reflect differences in flow resistance in the two sides of the coronary circulation during various phases of the cardiac cycle and explain the computational fluid dynamics findings observed in the Cabrol graft. One modification of the Cabrol technique is based on the use of separated graft conduits (i.e., "legs" technique) interposed between the coronary buttons and the main body of the aortic graft. Mills and colleagues described 10 cases in which this technique was successfully used (Figure 3B) [24], but they did not conduct longterm follow-up. This reconstruction, like the Cabrol operation, allows completion of the anastomoses between the side branch grafts and the coronaries without requiring extensive mobilization of the buttons, but it has the major advantage of preserving the physiology of independent left and right coronary perfusion.

In our experience, the use of a custom-made Dacron graft with prefabricated coronary branches allows successful aortic root reconstruction by applying these same principles. In the present series, there were no early or late complications related to compromise of coronary perfusion. Only one patient died 25 months after surgery due to stroke-related complications. Serial follow-up echocardiograms obtained for each patient showed no significant changes in overall ventricular function or any new wall motion abnormalities compared with the preoperative condition. Every patient underwent computed tomography follow-up to obtain imaging assessment of coronary flow. There was no evidence of coronary flow obstruction or formation of anastomotic pseudoaneurysms (Figure 5). This latter complication is most likely related to the use of the "inclusion" technique that is traditionally adopted with the Cabrol reconstruction $[13,19]$, but it may also be related to the fact that these patients have been subject to postoperative anticoagulation to lower the risk of Cabrol graft thrombosis. By virtue of preserving the physiology of coronary circulation, which prevents the unbalanced coronary flow distribution within the Cabrol graft, none of our patients required any perioperative anticoagulation treatment, and only long-term aspirin therapy was administered. 

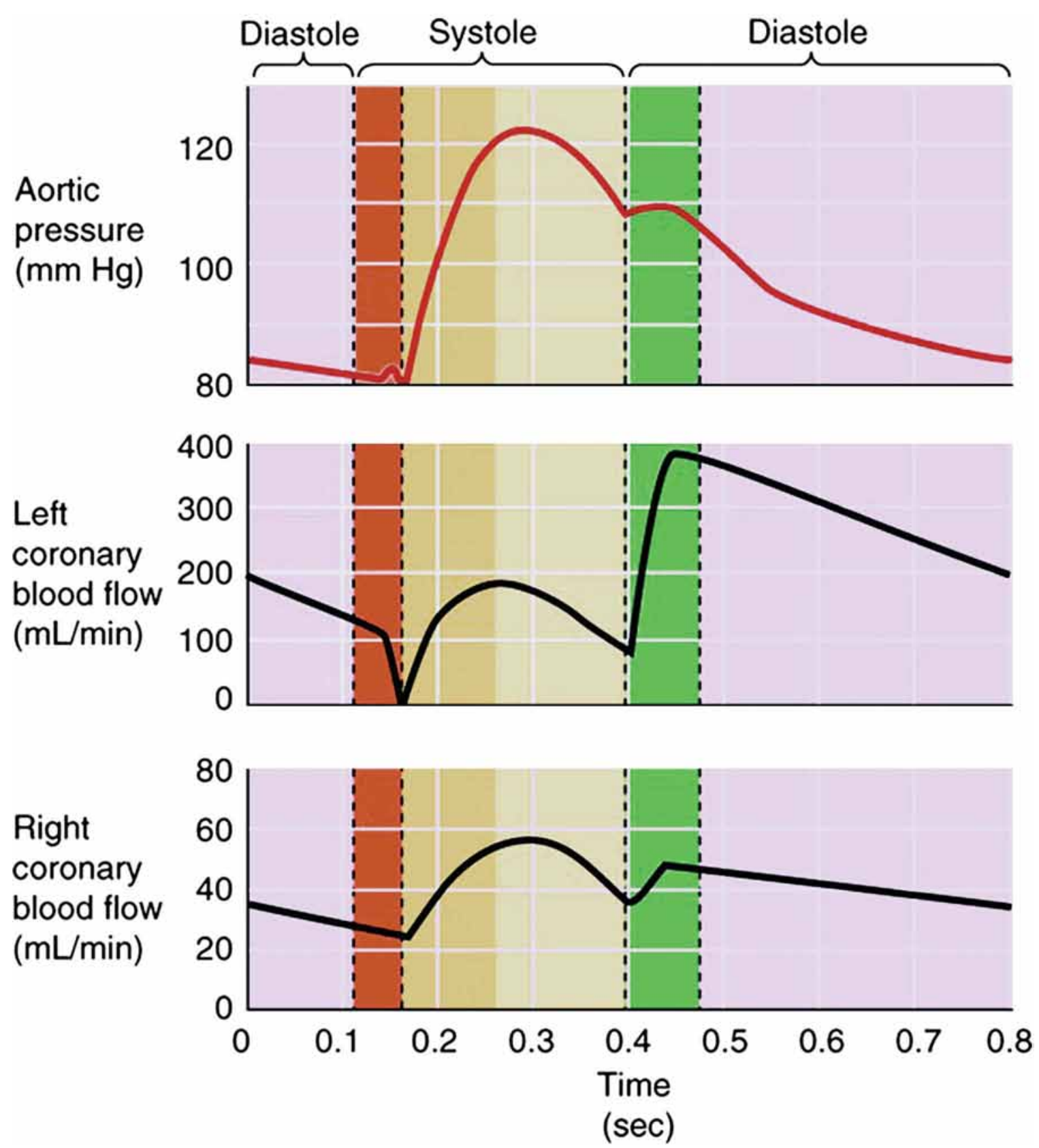

Figure 4. Characteristics of flow-dynamics of the left and right coronary circulation (reprinted with permission from Koeppen and Stenton [25]).

The use of this graft simplifies coronary reattachment, minimizing the need for coronary mobilization, and also facilitates the anastomotic technique. This is in accordance with our experience with total arch and thoracoabdominal aortic replacement, in which the routine use of multibranched prosthetic grafts allows direct anastomosis to the native branch vessels as compared to completing button and island patch anastomoses. Our series, although limited in number, included five patients with large aneurysms, and one acute Type A dissection complicated by damage of both coronary ostia. In a recent report of their midterm experience with a modified Cabrol procedure, Elefteriades and col- 


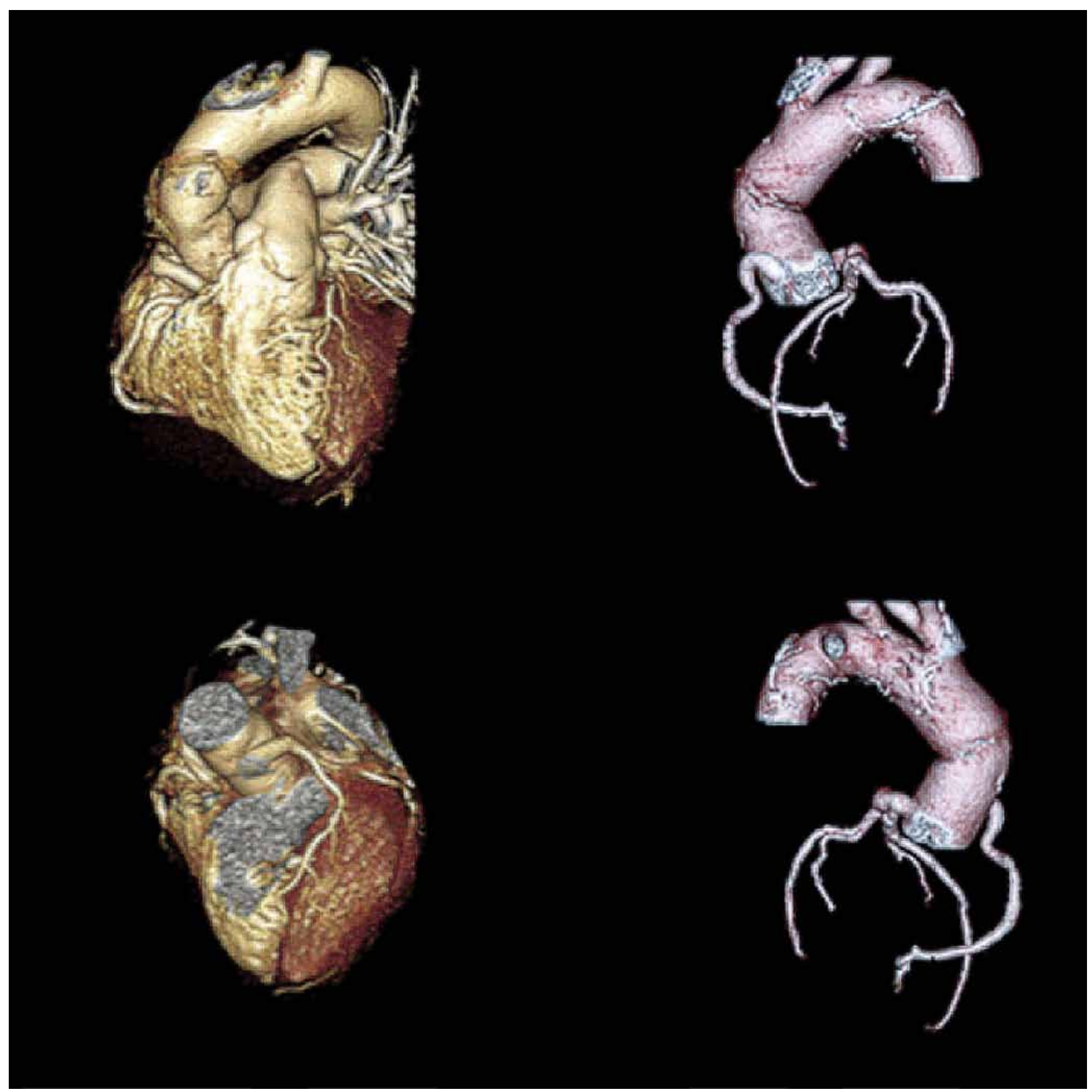

Figure 5. Three-dimensional reconstruction of computed tomographic coronary angiogram after aortic root replacement with the experimental modified Dacron graft demonstrating graft patency and no evidence of obstruction or anastomotic pseudoaneurysm formation.

leagues report the use of a variation of the Cabrol reconstruction in a non-negligible $11.5 \%$ of their root replacements, indicating that the challenge of coronary button preparation and reimplantation can be significant [13]. Accordingly, previous reports in the literature of numerous modifications of the coronary reimplantation technique aimed at preventing complications with coronary perfusion reiterate the significance of this problem. The use of an aortic root graft with prefabricated coronary branch- 
es eliminates the need for proximal anastomoses to the main body graft, as in the "legs" technique, and allows easier access to the coronary anastomoses, providing better exposure for repair in case of bleeding at an anastomotic site as compared to Cabrol and modified Bentall reconstructions [13]. The side-port branch gives options for direct graft cannulation or vent suction after reconstruction is completed. The graft does not include Valsalva's sinuses, which would have the conceptual advantage, especially in valve-sparing procedures, of reproducing more physiologic blood flow within the aortic root. Although this aspect could have an impact on valve durability by reducing hemodynamic stress on the valve leaflets, in our experience it may represent a challenge for the correct reimplantation of the leaflets within the prosthetic graft by having a predetermined height of reattachment of the commissures to the sinotubular junction, which could ultimately impair leaflet coaptation [11]. Also, features of the Valsalva's prosthesis in facilitating implantation of the coronaries, as in redo operation or in cases of porcelain aorta, are obviated by the presence of coronary side branches reaching to the coronary ostia without a need for extensive dissection and mobilization.

The main limitation of the present study is the small number of cases. Although we are not necessarily advocating for the use of this graft in all cases of ARR, we consider its use beneficial in cases where mobilization and reimplantation of the coronary buttons is anticipated to be challenging, such as for redo cases, calcified aortic roots, large aneurysms, and aortic dissections. We find that avoiding the need for coronary button mobilization and facilitating the anastomotic technique are favorable features of this novel graft that may ultimately result in more widespread utilization for routine ARR. Long-term follow-up with computed tomography and computational fluid dynamics is required to further assess the durability of this reconstruction.

\section{Conclusion}

The Cabrol procedure has been the operation of choice as an alternative to modified Bentall reconstruction for complex ARR. However, the occurrence of complications with the Cabrol interposition graft has favored the rise of various modifications of coronary reimplantation. Our experience with the use of a prosthetic aortic root graft with prefabricated coronary branches has shown good early and midterm results, suggesting its possible utilization on a larger scale.

\section{Conflict of Interest}

The authors have no conflict of interest relevant to this publication.

\section{Comment on this Article or Ask a Question}

\section{References}

1. Bachet J, Termignon JL, Goudot B, Dreyfus G, Piquois A, Brodaty D, et al. Aortic root replacement with a composite graft. Factors influencing immediate and long-term results. Eur J Cardiothorac Surg. 1996;10:207213. DOI: 10.1016/S1010-7940(96)80298-3

2. Kourliouros A, Soni M, Rasoli S, Grapsa J, Nihoyannopoulos P, O'Regan D, et al. Evolution and current applications of the Cabrol procedure and its modifications. Ann Thorac Surg. 2011;91:1636-1641. DOI: 10.1016/j.athoracsur.2011.01.061

3. Westaby S, Katsumata T, Vaccari G. Aortic root replacement with coronary button re-implantation: low risk and predictable outcome. Eur J Cardiothorac Surg. 2000;17:259-265. DOI: 10.1016/S10107940(00)00347-X
4. Shahriari A, Eng $M$, Tranquilli $M$, Elefteriades JA. Rescue coronary artery bypass grafting after aortic composite graft replacement. J Card Surg. 2009;24: 392-396. DOI: 10.1111/j.1540-8191.2008. 00762.x

5. Marino M, Cellini C, Tsiopoulos V, Pavoni $\mathrm{N}$, Zamparelli R, Corrado M, et al. A case of myocardial infarction effectively treated by emergency coronary stenting soon after a Bentall-De Bono aortic surgery. Cardiovasc Revasc Med. 2010;11:263.e5-9. DOI: 10.1016/j.carrev.2009.07.003

6. Ielasi $A$, Latib A, Montorfano $M$, Torracca L, Colombo A. Percutaneous treatment of iatrogenic left main ostial stenosis: after a Bentall operation. Tex Heart Inst J. 2012;39:144-145. PMID: 22412253
7. Worthley MI, Burgess J, Traboulsi M. Bilateral coronary ostial stenosis post-Bentall procedure: management options in the DES era. J Invasive Cardiol. 2005;17: 680-682. PMID: 16327054

8. Anastasius M, Hillis G, Yiannikas J. The left main complication of the Bentall's procedure. Cardiol Res. 2013;4:199-202. DOI: $10.4021 / \mathrm{cr} 285 \mathrm{w}$

9. Bernelli C, Bezante GP, Brunelli C, Balbi M. latrogenic left main coronary ostial stenosis: after a Bentall procedure in an asymptomatic young man. Tex Heart Inst J. 2012;39:393-397. PMID: 22719152

10. Kouchoukos NT, Wareing TH, Murphy SF, Perrillo JB. Sixteen-year experience with aortic root replacement. Results of 172 operations. Ann Surg. 1991;214:308-320. DOI: 


\subsection{7/00000658-199109000-00013}

11. Calcaterra D, Farivar RS, Parekh KR, Bashir M, Karam K, Turek JW. Technique of aortic root reconstruction using a new model of Dacron graft with prefabricated coronary branches. Innovations. 2014;9:451-453. DOI: 10.1097/IMI.0000000000000111

12. Bentall $H$, De Bono A. A technique for complete replacement of the ascending aorta. Thorax. 1968;23:338-339. DOI: 10.1136/thx.23.4.338

13. Ziganshin BA, Williams FE, Tranquilli $M$, Elefteriades JA. Midterm experience with modified Cabrol procedure: safe and durable for complex aortic root replacement. J Thorac Cardiovasc Surg. 2014;147:12331239. DOI: $10.1016 /$ j.jtcvs.2013.03.027

14. Westaby S, Katsumata T, and Vaccari G. Coronary reimplantation in aortic root replacement: a method to avoid tension. Ann Thorac Surg 1999;67:1176-1177. DOI: 10.1016/S0003-4975(99)00147-2

15. Nezafati P, Shomali A, Nezafati MH. A simplified modified Bentall technique for surgical reconstruction of the aortic root - short and long term outcomes. J Cardiothorac Surg. 2015;10:132-138. DOI: 10.1186/s13019-015-0336-4

16. Almuwaqqat Z, Tranquilli M, Elefteriades J. Anatomy of main coronary artery location: radial position around the aortic root circumference. Int J Angiol. 2012;21:125-128. DOI: 10.1055/s-0032-1315631
17. Grenon SM, Lachapelle K, Marcil M, Omeroglu A, Genest J, de Varennes B. Surgical strategies for severe calcification of the aorta (porcelain aorta) in two patients with homozygous familial hypercholesterolemia. Can J Cardiol. 2007;23:1159-1161. DOI: 10.1016/S0828282X(07)70889-9

18. Mossuto E, Milano A, Bortolotti U. The Cabrol technique for replacement of the aortic valve and totally calcified ascending aorta: a case report. J Heart Valve Dis. 1994;3:98-100. PMID: 8162226

19. Cabrol C, Pavie A, Gandjbakhch I, Villemot JP, Guiraudon G, Laughlin L, et al. Complete replacement of the ascending aorta with reimplantation of the coronary arteries: new surgical approach. J Thorac Cardiovasc Surg. 1981;81:309-315. PMID: 7453242

20. Gelsomino S, Frassani R, Da Col P, Morocutti G, Masullo G, Spedicato L, et al. A longterm experience with the Cabrol root replacement technique for the management of ascending aortic aneurysms and dissections. Ann Thorac Surg. 2003;75:126-131. DOI: 10.1016/S0003-4975(02)04284-4

21. Witzenbichler B, Schwimmbeck $P$, Schultheiss HP. Images in cardiovascular medicine. Myocardial infarction caused by occlusion of Cabrol conduit graft. Circulation. 2005;112:e79-80. DOI: 10.1161/ CIRCULATIONAHA.104.500215

22. Knight J, Baumuller S, Kurtcuoglu V, Turina
$M$, Turina J, Schurr $U$, et al. Long-term follow-up, computed tomography, and computational fluid dynamics of the Cabrol procedure. J Thorac Cardiovasc Surg. 2010;139:1602-1608. DOI: 10.1016/j. jtcvs.2009.09.023

23. Patel D, Arteaga RB, Robinson VJ, Patel NA, Kapoor D. Angina, an unusual and late complication of the Cabrol procedure: a case report and review of the literature. Am J Med Sci. 2008;335: 151-153. DOI: 10.1097/MAJ.0b013e3180a $6 f 13 b$

24. Mills NL, Morgenstern DA, Gaudiani VA, Ordoyne F. "Legs" technique for management of widely separated coronary arteries during ascending aortic repair. Ann Thorac Surg. 1996;61:869-874. DOI: 10.1016/00034975(95)01185-4

25. Koeppen BM, Stenton BA. Regulation of heart and vasculature. Berne and Levy Physiology 6th Edition, 2010; 370-392.

Cite this article as: Calcaterra $D$, Jazayeri MA, Turek JW, Parekh KR, Bashir M, Karam K, Farivar RS. Aortic Root Reconstruction with a New Dacron Graft Featuring Prefabricated Coronary Side Branches: Lessons Learned from the Cabrol Procedure. AORTA (Stamford). 2017;5(1):1-10. DOI: http://dx.doi.org/ 10.12945/j.aorta.2017.16.023 